\title{
Assessment of Early Impact of Cyclone Thane on Physical and Psychosocial Environment
}

\author{
B. Adhisivam • Fromsi Lukose • L. Subitha • \\ B. Vishnu Bhat
}

Received: 2 September 2013 / Accepted: 4 February 2014 / Published online: 22 March 2014

(C) Dr. K C Chaudhuri Foundation 2014

To the Editor: Disasters have the greatest effect on the most vulnerable groups, especially children [1-3]. Cyclone Thane hit the coast of Tamil Nadu and Pondicherry on 29th and 30th of December 2011 and destroyed houses, boats, standing crops, livestock and livelihoods. A questionnaire based study was conducted at JIPMER, Pondicherry 2 weeks after the cyclone to study its early impact of on the physical and psychosocial environment of children. Data including demographic parameters, feeding, damage to school and house, problems of electricity, water, transport, telecommunication and relief measures related to the disaster were collected in a structured proforma from 100 parentchild dyads from Thane affected areas. Likert scale $(0-3)$ was used to quantify stress among parents and children. There was significant damage to home and schools secondary to falling of trees. Mean duration of return to normalcy for water supply, electricity and transport were $6.5,10.8$ and $3.2 \mathrm{~d}$ respectively. Cost of candles, kerosene and milk was significantly increased. Infants and young children were breastfed as usual and fed with the routine food items available at home during the first week after Thane. Only $35 \%$ had used boiled water for drinking. Cow's milk was not available for young children for $3-5 \mathrm{~d}$ after the disaster.

B. Adhisivam $(\bowtie) \cdot$ F. Lukose $\cdot$ B. V. Bhat

Department of Pediatrics, Jawaharlal Institute of Postgraduate

Medical Education and Research (JIPMER), Pondicherry 605 006, India

e-mail: adhisivam1975@yahoo.co.uk

\section{Subitha}

Department of Preventive and Social Medicine, Jawaharlal Institute of Postgraduate Medical Education and Research (JIPMER), Pondicherry, India
No breastmilk substitutes (BMS) or feeding bottles were distributed. $39 \%$ adults and $6 \%$ children had minor illness which included $49 \%$ upper respiratory tract infection, $33 \%$ lower respiratory tract infection and $18 \%$ diarrhea. Significant level of stress was noted among parents and children. Disruption of water supply for more than $2 \mathrm{~d}$ and damage to house and school were significantly associated with parental stress. This study showed that Cyclone Thane had significant early impact on the physical and psychosocial environment of children. However, the long term effects including post traumatic stress disorder need to be assessed. Psychological first aid in the immediate aftermath of disaster may reduce the initial distress and foster short and long-term adaptive functioning [4]. Careful tracking of important health and mental health problems that confound recovery may lead to appropriate interventions that can help reduce morbidity associated with the inevitable next catastrophe [5].

Conflict of Interest None.

Role of Funding Source None.

\section{References}

1. Redmond AD. Natural disasters. BMJ. 2005;330:1259-61.

2. Adhisivam B, Srinivasan S, Soudarssanane MB, Deepak Amalnath S, Nirmal Kumar A. Feeding of infants and young children in tsunami affected villages in Pondicherry. Indian Pediatr. 2006;43:724-7.

3. Brennan RJ, Rimba K. Rapid health assessment in Aceh Jaya District, Indonesia, following the December 26 tsunami. Emerg Med Australas. 2005; 17:341-50.

4. The Psychological First Aid for Medical Reserve Corps Field Operations Guide. http://www.naccho.org/topics/emergency/MRC/ resources/upload/MRC-PFA-Field-Operations-Guide.pdf Accessed 23 Jun 2013.

5. Redlener I, Reilly MJ. Lessons from Sandy-preparing health systems for future disasters. N Engl J Med. 2012;367:2269-71. 